\title{
Comparing and Prioritizing the Factors Affecting Purchase Decisions in Innovation Adoption in a Post-Secondary Educational Setting
}

\author{
Katherine C. Lafreniere, M. Gordon Hunter, and \\ Sameer Deshpande \\ University of Lethbridge, Lethbridge, AB, Canada \\ katie.lafreniere@uleth.ca; ghunter@uleth.ca; \\ sameer.deshpande@uleth.ca
}

\begin{abstract}
This study explores the factors influencing the purchase decision in innovation adoption in the public sector. Qualitative data, using in-depth, semi-structured interviews were gathered from IT professionals at a post-secondary institution who regularly make purchase decisions. Participants were found to use a staged approach for purchase decisions in innovation adoption. Purchase options that did not meet the minimum requirements set out by the non-compensatory factors (budget, redundancy, organizational strategy, life expectancy, time, compatibility, and reputable vendor) were immediately eliminated. The remaining options were evaluated by weighted adding factors (complexity, social pressure, IT support, price, and perceived innovation characteristics) to obtain an overall value for each option. The option with the highest overall value was then selected. These findings are consistent with the classic decision strategies in the consumer choice literature. The significant contribution of this research project is a more comprehensive understanding of the different factors and their level of impact on purchase decisions in innovation adoption. Sales personnel can use these findings to explain adoption and non-adoption of an innovation. Innovations and their corresponding marketing strategy can be developed accordingly to avoid non-adoption.
\end{abstract}

Keywords: Purchase decisions, Innovation Adoption, Decision Strategies, Public Sector, Technology Adoption, IS, IT, Decision Making, Narrative Inquiry

\section{Introduction}

The innovation adoption process is among the most studied topics in IT research (Hirschheim, 2007; Travica, 2008; Venkatesh, Davis, \& Morris, 2007; Williams, Dwivedi, Lal, \& Schwarz, 2009; Wolfe, 1994). "It is a process through which an individual or other decision making unit

Material published as part of this publication, either on-line or in print, is copyrighted by the Informing Science Institute. Permission to make digital or paper copy of part or all of these works for personal or classroom use is granted without fee provided that the copies are not made or distributed for profit or commercial advantage AND that copies 1) bear this notice in full and 2) give the full citation on the first page. It is permissible to abstract these works so long as credit is given. To copy in all other cases or to republish or to post on a server or to redistribute to lists requires specific permission and payment of a fee. Contact Publisher@InformingScience.org to request redistribution permission. passes from first knowledge of an innovation; to forming an attitude towards the innovation; to a decision to adopt or reject; to implementation of the new idea; and to confirmation of this decision" (Rogers, 1995a, p. 21). However, recent reviews of the adoption literature suggest that there are still many opportunities for increasing knowledge of the innovation adoption process (Hirschheim, 2007; Ramdani \& 
Kawalek, 2007; Williams et al., 2009). Specifically, findings suggest that innovation adoption and non-adoption is not only driven by different factors (e.g., budget, redundancy) (Dewan \& Riggins, 2005; Eckhardt, Laumer, \& Weitzel, 2009; Lapointe \& Rivard, 2007; Venkatesh \& Brown, 2001) but also influenced by some factors more than others (Anderson, Thomson, \& Wynstra, 2000; Eckhardt et al., 2009; Elpez \& Fink, 2006). However, there has yet to be a comprehensive investigation of the different levels of impact that these factors may have on the innovation adoption process.

The purpose of this study was to contribute to a more comprehensive understanding of the different factors and their level of impact on the innovation adoption process. This study compares and analyzes the factors influencing adoption of IT hardware in a post-secondary educational setting. Post-secondary institutions along with other public sector organizations are major investors in IT and rely heavily on IT to remain efficient and effective (Elpez \& Fink, 2006). This perspective can not only expand the innovation adoption literature but also enhance marketing strategies used to influence innovation adoption.

Although the innovation adoption process at the organizational level consists of different stages (awareness, consideration, intention, adoption decision, continued use), most studies focus on the adoption decision (Frambach \& Schillewaert, 2002). This study focuses on intention and the adoption decision. Figure 1 illustrates the innovation adoption process at the organizational level as described in the adoption literature (e.g., Frambach \& Schillewaert, 2002; Rogers 1995a; Zaltman, Duncan, \& Holbek, 1973). Given the major activities in the intention and adoption stage, we conceptualize that evaluating purchase options would occur during the intention stage and purchasing the innovation would occur during the adoption decision stage in the innovation adoption process. Given that the decision to make use of a product often involves the decision to purchase the product, it can be understood that some factors affecting the purchase decision may also affect the adoption decision. Some studies employ the terms purchase and adoption interchangeably (see Cabral, Salant, \& Woroch, 1999). Our focus within the overall innovation adoption process is on the decision to purchase. Although we view these activities as conceptually distinct, we recognize that both activities may occur in the same innovation adoption process.

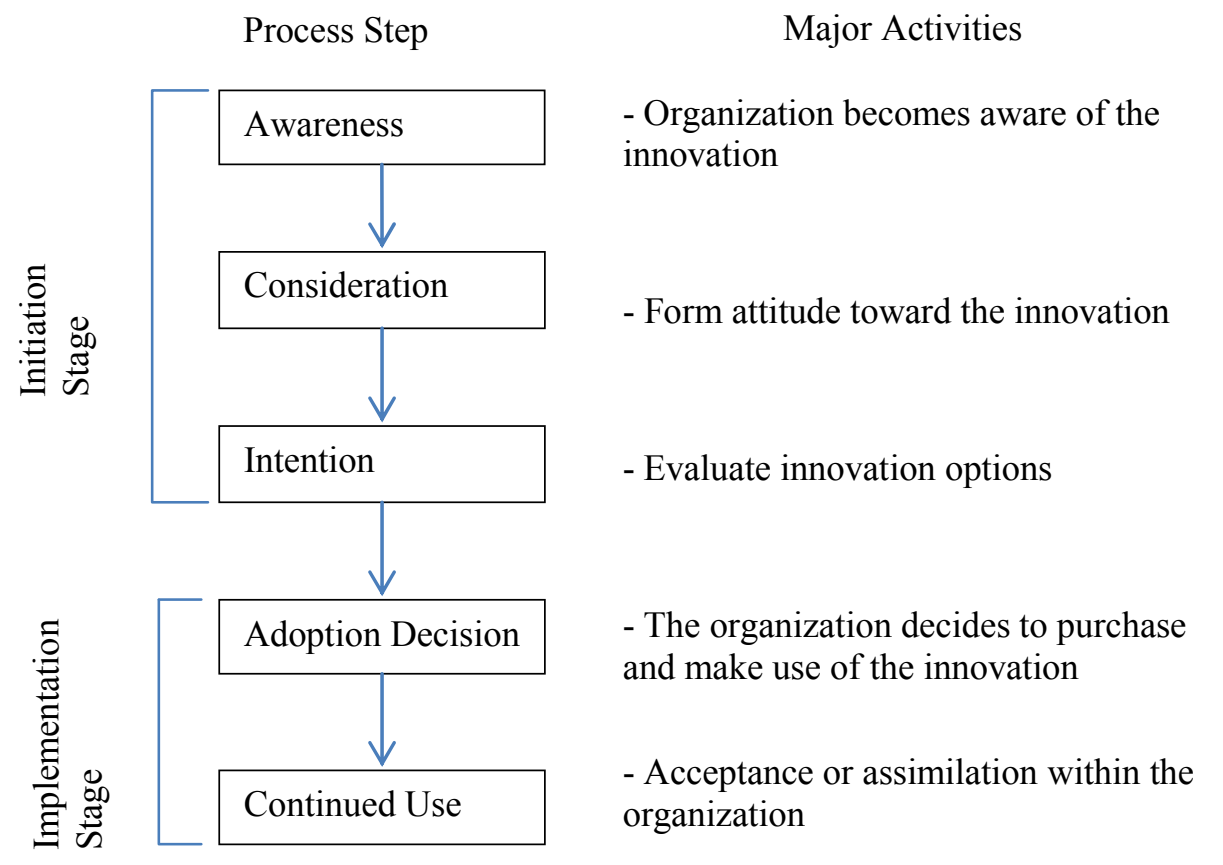

Figure 1. The Innovation Adoption Process at the Organizational level 
Lafreniere, Hunter, \& Deshpande

This article begins with a literature review of the factors and theories that affect innovation adoption as well as a discussion of the research questions. The method section outlines how the research questions were addressed. Finally, the results of the empirical study are reported, and the implications for innovation adoption research are discussed.

\section{Literature Review}

In this section, the theories and factors related to innovation adoption and non-adoption are introduced in order to provide a context for the research questions in this investigation.

\section{The Innovation Adoption Process}

Documentation of the innovation adoption process started to develop when researchers recognized that marketers must understand the potential customers and the factors influencing their purchase decision in order to be successful in bringing innovations to market (Frambach \& Schillewaert, 2002). The initial innovation adoption models considered factors such as user satisfaction and attitude (Ramdani \& Kawalek, 2007; Venkatesh et al., 2007). Since then, researchers have empirically tested adoption models based on theories mostly from the fields of social psychology and behavioral science (Eckhardt et al., 2009; Ramdani \& Kawalek, 2007).

The most prominent theories include the Technology Acceptance Model (TAM), the Theory of Reasoned Action (TRA), and the Theory of Planned Behavior (TPB) (Ajzen, 1991). TAM posits that perceived ease of use and usefulness determines innovation adoption (Davis, 1989). TRA argues that attitude (favorable/unfavorable) towards the behavior and subjective norms (perceived social pressure to adopt) are the two main factors impacting behavior intention (Fishbein \& Ajzen, 1975). TPB also considers attitude towards the behavior and subjective norms as variables that determine innovation adoption. However, this theory considers a third variable entitled behavioral control (ease/difficulty in performing the behavior) (Ajzen, 1985).

Although these theories advanced the knowledge of some determinants of innovation adoption, researchers have valid arguments against their ability to fully explain the innovation adoption process (Ramdani \& Kawalek, 2007). Specifically, Davis, Bagozzi, and Warshaw (1989) posit that TRA only partially explains the determinants of adoption behavior, because it highlights only the overarching determinants. Unlike TRA, TAM explains specific attributes to innovation adoption. However, it doesn't incorporate all the factors influencing innovation adoption (Ramdani \& Kawalek, 2007). In 2001, Mathieson, Peacock, and Chin (as cited in Ramdani \& Kawalek, 2007) criticized TPB for not being specific to IT usage and less parsimonious than TAM. TPB also requires distinct operationalizations in every different situation in which it could be applied. Overall, many researchers are concerned that these highly accepted theories have led to a lack of original research in innovation adoption (Benbasat \& Barki, 2007; Williams et al., 2009).

As adoption research progressed, other factors empirically demonstrated an influence on innovation adoption. In a broad sense, researchers have considered five categories that account for all the pertinent factors that affect the innovation adoption process. These categories relate to the innovation/technology, time, social pressure, organizational aspects, and decision strategies. Each factor is discussed in the following sub-sections.

\section{Innovation/Technology Factors}

In the adoption and diffusion literature, attributes of the innovation may affect the decision maker's evaluation of and propensity to adopt a new product (Frambach \& Schillewaert, 2002; Holak, Lehmann, \& Sultan, 1987; Karahanna, Straub, \& Chervany, 1999; Ostlund, 1974; Rogers, 1995a). Perceived innovation characteristics are considered a factor in the innovation adoption process because of the notion that organizations are faced with multiple alternatives which are 
examined before a final decision is made (Ozanne \& Churchill, 1971). In the IT context, Waarts, van Everdingen, and van Hillegersberg (2002) defined innovation characteristics as the firms' ideas about the value of the innovation in terms of the advantages and disadvantages compared to existing solutions and its compatibility with current IT infrastructure.

In the diffusion literature, attributes of the innovation which may affect adoption include relative advantage, image, compatibility, complexity, trialability, visibility, and result demonstratability (Frambach \& Schillewaert, 2002; Iacovou, Benbasat, \& Dexter, 1995; Karahanna et al., 1999; Rogers, 1995a). Each attribute is described in Table 1. According to the diffusion model, innovations which are perceived by decision makers as having greater relative advantage, compatibility, trialability, observability, and less complexity will be adopted more rapidly than other innovations (Rogers, 1995b, p. 990). However, a meta-analysis conducted by Tornatzky and Klein (1982) indicated that only relative advantage, complexity and compatibility were consistently related to adoption.

\section{Table 1. Definitions of the Innovation Attributes that may affect Adoption (Karahanna et al., 1999)}

\begin{tabular}{|l|l|}
\hline Attribute & Definition \\
\hline $\begin{array}{l}\text { Relative Advantage } \\
\text { (Perceived Usefulness) }\end{array}$ & $\begin{array}{l}\text { the degree to which adopting/using the IT innovation is perceived as } \\
\text { being better than using the practice it supersedes }\end{array}$ \\
\hline Image & $\begin{array}{l}\text { the degree to which adoption/usage of the innovation is perceived to } \\
\text { enhance one's image or status in one's social system }\end{array}$ \\
\hline Compatibility & $\begin{array}{l}\text { the degree to which adopting the IT innovation is compatible with what } \\
\text { people do }\end{array}$ \\
\hline $\begin{array}{l}\text { Complexity } \\
\text { (Ease of Use) }\end{array}$ & the degree to which using a particular system is free of effort \\
\hline Trialability & $\begin{array}{l}\text { the degree to which one can experiment with an innovation on a limited } \\
\text { basis before making an adoption or rejection decision }\end{array}$ \\
\hline Visibility & the degree to which the innovation is visible in the organization \\
\hline $\begin{array}{l}\text { Observability (Result } \\
\text { Demonstratability) }\end{array}$ & $\begin{array}{l}\text { the degree to which the results of adopting/using the IT innovation are } \\
\text { observable and communicable to others }\end{array}$ \\
\hline
\end{tabular}

Relative advantage is often illustrated as the perceived usefulness, including economic incentives, of adopting the innovation exceeding that of the alternatives (Frambach \& Schillewaert, 2002). However, Anderson, Thomson, and Wynstra (2000) found that even attributes of relative advantage, such as price and value, cannot be considered equal in the mind of the decision maker. Value refers to the total functionality of the product offering. It is realized in terms of the economic, technical, service, and social benefits that an organization receives over time during use of the offering (Anderson et al., 2000). Price is the monetary amount that an organization pays to acquire the innovation. Price is distinct from value because of the notion that changing the price of a product does not change value (Anderson et al., 2000). They also found that purchasing managers did not regard value and price the same even when they were monetarily equivalent. Purchasing managers were found to make judgments more likely on price rather than value in negatively framed problems but not in the positively framed problems. For example, purchase managers are more sensitive to price increases (negatively framed problems) than to price decreases (positively framed problems) and prefer to choose offerings that represent no or the smallest price 
increase. Anderson and associates (2000) suggest that innovation attributes, such as value and price, have different levels of influence on the final purchasing decision.

\section{Time Factors}

Time factors have been studied from three perspectives. The first perspective is based on the notion that organizations generate a strategic advantage by basing decisions on either accumulated knowledge over time or long-term, strategic intentions. As such, firms may develop either a past or future oriented reference point to make decisions. According to Fiegenbaum, Hart, and Schendel (1996), past oriented organizations look at past performance to evaluate alternatives. They make decisions based on their corporate identity, values, and philosophy. A future oriented organization looks at strategic intent to evaluate alternatives. They make decisions based on the future, long-term purpose, mission, and direction of the organization (Fiegenbaum et al., 1996, p. 227).

The second perspective is based on the notion that the driving factors that impact a decision change over time. For example, Waarts, et al. (2002) argued that the effect size of innovation characteristics, internal environment, external environment, and adopter changed over time depending on the level of diffusion of the prospect in the market. As such, early product adopters are sensitive to different factors than late product adopters. Thus, marketing tactics should change as an innovation moves along the product life cycle.

The third perspective suggests that marketers should also be conscious about the timeframe available to project their message to a specific organization. According to Ozanne and Churchill (1971), organizations take different amounts of time to make a purchase decision. The amount of time used to make a decision affects the number of competitors able to present their prospect as well as the level of influence a marketer may have on a decision. As a result, marketers need to be conscious of not only the driving factors influencing a decision at a certain point in time but also the amount of time available to form an argument for a prospect. Furthermore, in situations involving time pressure, decision makers accelerate their processing, become more selective, and change their decision strategies (Payne, Bettman, \& Schkade, 1988).

\section{Social Pressure Factors}

While being employed in adoption and diffusion research for over almost 20 years, social influence and peer group pressure are still among the most frequently discussed topics (Eckhardt et al., 2009). The importance of social pressure in the innovation adoption process stems from the perception that, in working organizations, decisions are made in either the presence of others or with the knowledge that they will have to be understood, or implemented, or approved by others (Burns \& Stalker, 1961). Social groups that may exert social pressure on the decision maker include, but are not limited to, colleagues, supervisors, end users, IT department (Eckhardt et al., 2009), computer specialists, top management, peers, friends (Karahanna et al., 1999), suppliers (Waarts et al., 2002), competitors (Frambach \& Schillewaert, 2002), partners (Iacovou et al., 1995), governments, and consultants (Del Aguila-Obra \& Padilla-Meléndez, 2006).

Due to the high acceptance of TRA and TPB in the adoption and diffusion literature, social pressure is more commonly measured as 'subjective norm'. However, it has also been referred to as external factors (e.g. Del Aguila-Obra \& Padilla-Meléndez, 2006). Subjective norm refers to the person's perception that most people important to him/her think he/she should or should not perform the behavior in question (Fishbein \& Ajzen, 1975). However, this definition has received substantial criticism because it combines various groups of influencers, whose opinions differ or at least vary in size, into one group of 'important others.' As a result, the social pressure construct has been difficult to measure and was found to be not significant in several innovation adoption 
studies (Eckhardt et al., 2009). Thus, innovation adoption research should consider the influence of each group independently. These arguments correspond to the findings that adoption and nonadoption are impacted by different social groups (Eckhardt et al., 2009).

Eckhardt and associates (2009) also found that the strongest social influence on adopters and nonadopters comes from the group of superiors, followed by colleagues in the same department as well as the IT department. However, social pressure as a whole has been found to be less important than technological factors in the innovation adoption process (Teo, Tan, \& Buk, 1997). These findings contradict those of Iacovou and associates (1995) who found social pressure to be one of the biggest factors influencing innovation adoption. Overall, the literature suggests that the factors and their corresponding attributes influencing innovation adoption process cannot be considered equally.

\section{Organizational Factors}

Qualls and Puto (1989) suggest that organizational attributes (e.g. resource constraints) have no direct control but nonetheless reflect on performance. Some characteristics of the organization that impacts the organizational decision include size, structure, innovativeness (Frambach \& Schillewaert, 2002), IT resources (Bunn, 1993; Fiegenbaum et al., 1996), general attitude to IT (Waarts et al., 2002), level of IT knowledge (Thong, 1999), management capabilities (Del Aguila-Obra \& Padilla-Meléndez, 2006), IT support, and budget (Bouchbout \& Alimazighi, 2008).

Research has also found that organizational attributes do not equally affect the innovation adoption process. For example, Del Aguila-Obra and Padilla-Meléndez (2006) found that the most important organizational attributes were IT resources and managerial capabilities. Furthermore, size affected the impact that managerial capabilities had on the final decision because smaller firms usually have fewer managerial capabilities (Del Aguila-Obra \& Padilla-Meléndez, 2006). Thus, some organizational attributes not only have different levels of impact on the final decision but also affect the influence of other organizational attributes.

By reviewing the most cited factors in innovation adoption processes, it can be seen that some factors not only have different levels of impact on the final decision but also affect the impact that other factors may have on the final decision. Furthermore, different factors affect adoption and non-adoption. The following section discusses decision strategy theories that may further explain the relationship of attributes in the innovation adoption process.

\section{Decision Strategies}

Most of the innovation adoption research has been restricted to identifying the factors affecting the final purchase decision. As a result, there has yet to be a comprehensive investigation of the different levels of impact that these factors may have on the innovation adoption process. Despite this limitation in innovation adoption research, the concept of prioritizing factors is well developed in the consumer choice literature under decision strategies. It can be understood that some factors affecting consumer choice may also affect the innovation adoption process. The most relevant decision strategies are discussed below (see Bettman, Luce, \& Payne, 1998, for a more comprehensive understanding of different decision strategies).

The weighted adding strategy is a classic decision strategy in the consumer choice literature. It is assumed that a decision maker can assess the importance of each factor and assign a subjective value to each possible factor level. In this strategy, the decision maker considers one option at a time, examining each attribute for that option, multiplying each attribute's assigned value times its importance weight (e.g. multiplying the subjective value of innovation compatibility with the current system by the importance of the innovation's compatibility) and summing these products 
across all of the attributes to obtain an overall value for each option. The option with the highest value would then be chosen (Bettman et al., 1998).

Another classic decision strategy is called Satisficing (Simon, 1955). In this strategy, options are considered sequentially, in the order in which they occur in the choice set. The value for each attribute for the option currently under consideration is considered to see whether it meets a predetermined cutoff level for that attribute. If any key attribute fails to meet the cutoff level, that option is rejected and the next option is considered (Bettman et al., 1998). For example, innovation A might be eliminated because it is not compatible with the current system. The first option that passes the cutoffs for all attributes is selected.

Elimination-by-aspects (EBA) rejects options that do not meet a minimum cutoff value for the most important attribute. This elimination process is then repeated for the second most important attribute. This process continues until there is only one option remaining (Tversky, 1972). For

example, suppose that a decision maker's two most important attributes are compatibility and life expectancy, in that order. The decision maker would first process compatibility, rejecting any innovation that was not compatible with the current system. The decision maker would then consider the life expectancy of the remaining options. If the consideration of life expectancy resulted in only one available option, the final decision would be to select that option.

In 1976, Payne (as cited in Bettman et al., 1998) argued that decision makers can also use a "combined strategy." A typical combined strategy has an initial phase in which some options are eliminated and a second phase where the remaining options are analyzed in more detail. For example, EBA may be used initially to reduce the number of options to two or three. This reduction is then followed by a compensatory strategy such as weighted adding to select from among the remaining options (Bettman et al., 1998).

Although these decision strategies provide a better understanding of prioritizing attributes, they are not specific to IT usage and, thus, a more comprehensive decision strategy for innovation adoption is required. Taking into account the lack of research on the different levels of impact that factors may have on the innovation adoption process in the public sector, an exploratory study was conducted. Therefore, the research questions are as follows:

1. How do IT professionals in a post-secondary educational setting describe their purchase decision regarding an innovation?

2. Can different levels of impact be identified with each factor influencing the purchase decision in innovation adoption?

3. Is there a decision strategy that best describes the purchase decision in innovation adoption?

\section{Method}

Guided by the qualitative paradigm, the design of this study focused on the collection of stories from IT professionals in the public sector who regularly make IT purchase decisions, which employs an analysis of narratives as the methodological approach (Eriksson \& Kovalainen, 2008). Such an approach allows for the emergence of multiple themes created by the participants themselves (Eriksson \& Kovalainen, 2008, p. 219). This approach involves the documentation of narratives and focuses on the particularity of individual experience in unique historical and societal locations and processes, or on the retelling of culturally and socially shared grand narratives (Eriksson \& Kovalainen, 2008). The interviews were designed to elicit a narrative regarding how the participants thought about and described their decision making process related to IT purchases of computer hardware, how they perceived their options, what preexisting factors influenced their decision, what type of information gathering process about the computer hardware was per- 
formed, whether or not their perceptions changed at all over the decision making process, and if so, what caused them to change, and finally, how their choice compared to the other alternatives.

Selective sampling procedures were used to determine which IT decision makers would participate in the study. Selective sampling refers to a decision made prior to beginning a study to sample participants according to an initial set of criteria (Gladstone, Dupuis, \& Wexler, 2006). The units of analyses comprised of fifteen different purchase decisions that made participants feel either comfortable or apprehensive. The seven participants in this study were IT employees from different departments at one post-secondary institution who regularly make decisions on whether or not to purchase computer hardware (see Table 2). The participants had experience making IT purchases for at least one year. Selective sampling allowed this study to focus on decision makers who know the topic, while capturing emerging themes related to their experience.

Table 2. Participants and their Expertise in Purchase Decisions

\begin{tabular}{|l|l|l|}
\hline Pseudonym & Position & Expertise \\
\hline Andy & Technology Services Manager & 9 years \\
\hline Bob & Systems Manager & 26 years \\
\hline Cam & Client Services Manager & 12 years \\
\hline Dale & Purchasing Agent & 3 years \\
\hline Evan & Systems Support Specialist & 8 years \\
\hline Fred & Department Director & 9 years \\
\hline Garth & System Administrator & 10 years \\
\hline
\end{tabular}

Semi-structured interviews were conducted in person. Participants were contacted by e-mail and the study was described to them. If they were interested in participating, an interview time was arranged. There were no participants who withdrew from this study. Prior to each interview, participants were informed about confidentiality and anonymity and signed consent forms. Interviews were, on average, approximately an hour in length and audio recorded. Each participant discussed at least two purchase decisions: a comfortable adoption decision and an apprehensive adoption decision. Transcripts were then prepared and actual names were replaced by pseudonyms.

Given that the adoption of an innovation entails uncertainty (Nooteboom, 1989), we compared comfortable decisions versus apprehensive decisions in order to understand how perceived uncertainty may affect the innovation adoption process. However, we found that decision strategies were used to alleviate perceived risk among the respondents. The development of the decision strategies as a theoretical explanation became clearer and more refined as interviews progressed, and thus the notion of using a decision strategy to understand the innovation adoption process evolved.

Thematic categories relating to the decision making process and to factors associated with influencing the final decision were inductively derived from the data using a theoretically-based, thematic analysis (Eriksson \& Kovalainen, 2008). The thematic analysis serves to examine the narratives as they are told by the participants in order to find patterns or themes (Eriksson \& Kovalainen, 2008, p. 219). Audio recordings and interview notes were analyzed for thematic categories in a 5 step process (McCracken, 1988). First, the data were observed in their entirety, with observations being made. The second step developed these observations, initially by themselves, and then according to the evidence in the data, and consequently according to the previous litera- 
ture. The third step examined the interconnection between the observations made in the previous step. The fourth step took all the observations from the previous steps and subjected them to collective scrutiny according to what the literature says ought to be there, how the decision making process is constituted in the researcher's experience, and what took place in the interview itself. Finally, the fifth step reviewed the previous conclusions in order to discuss developed properties of the decision making process within the group under study (McCracken, 1988).

Transferability (Guba \& Lincoln, 1989) was enhanced by comparing the results to previous research related to the innovation adoption process and decision strategies. Trustworthiness (Lincoln \& Guba, 1985) was established by concerted efforts to develop a trusting relationship

with participants. For example, questions were asked as part of a conversational, mutual exchange that allowed participants to take the role of "storyteller" and to present their experiences in the form of narratives (Gladstone et al., 2006). As recommended by Jeyaraj, Rottman, \& Lacity (2006), recall bias was accounted for by discussing IT innovations that were actually used in the organization.

\section{Findings}

In general, participants were found to use a 'combined strategy' (Payne, 1976) in order to facilitate purchase decisions in innovation adoption. Participants recalled undergoing two phases of elimination when they were evaluating innovation options (Intention stage). In the first phase, some options were eliminated using a non-compensatory strategy. In the second phase, the remaining options were analyzed in more detail using a 'weighted adding strategy' (see Figure 2). A non-compensatory strategy occurs when a good value on one attribute cannot make up for a poor value on another (Bettman et al., 1998). For example, if a participant decides to choose the cheapest option, then the innovation with the lowest price will be chosen regardless of its compatibility or efficiency costs. A non-compensatory strategy is consistent with decision strategies such as EBA and Satisficing (Bettman et al., 1998). A participant we will name Andy, purposely selected an option based on vendor experience regardless of cost or innovation features. His thoughts were:

We actually selected the vendor, not from a cost or feature set perspective, but primarily because of the resources that they were going to apply to this project. The person that was going to do this had almost five times the experience than anybody else.

If there were still purchase options available after the non-compensatory strategy, a second step of elimination occurred where the remaining options were analyzed in more detail. In this elimination phase, options were assessed according to the 'weighted adding strategy.' Dale, who had multiple options available after accounting for price, described the second elimination phase in the following way:

If there's a difference of $\$ 100$, then obviously price isn't a factor. Then we start looking at when we can get the item... if we can get it right away or if it's going to take a month to get here... how much shipping is going to be... Shipping can sometimes be $\$ 500$ on top of what the value would be or sometimes they'll offer free shipping. And then discounts. Sometimes companies will give universities huge discounts or they'll come down and give free training.

The weighted adding strategy is apparent by the decision maker's attempt to describe how some attributes weighed more than others in the assessment of each option. An option that rates low in type of equipment will create a lower overall value. 
Innovation Adoption Process

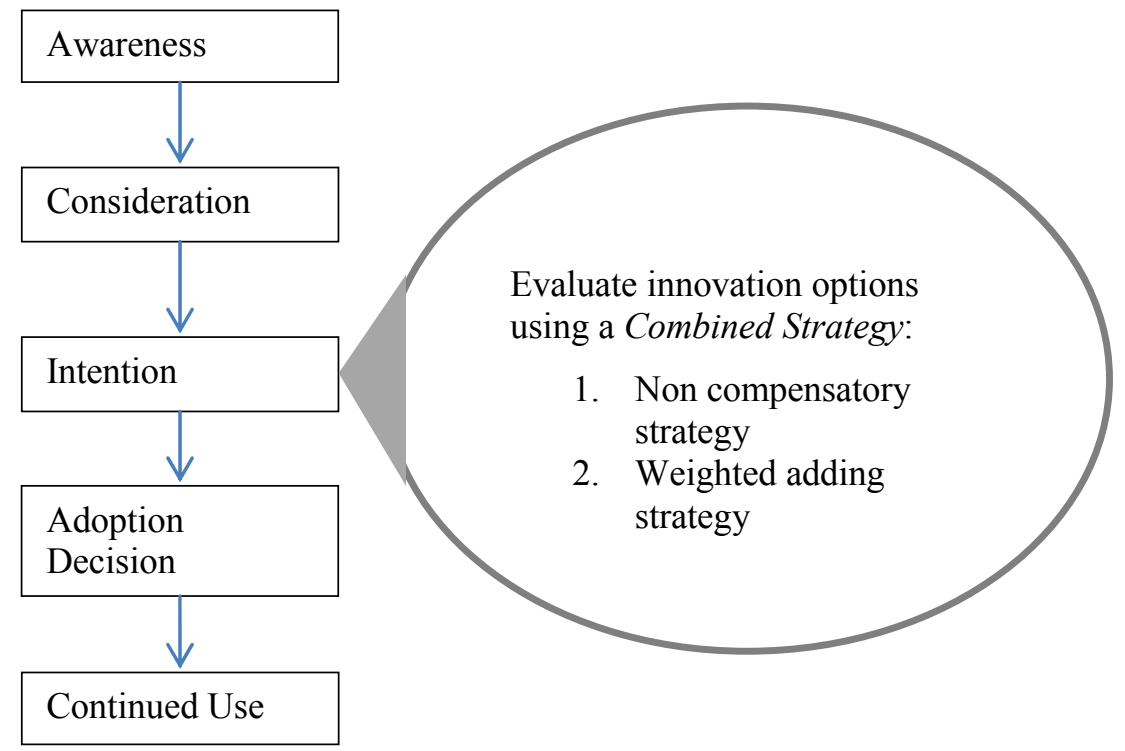

Figure 2. Using the Combined Strategy in the Innovation Adoption Process

In light of the combined strategy used by the participants, this study prioritized the factors of the purchase decision process in innovation adoption by the two decision strategies: (1) noncompensatory factors, and (2) weighted adding factors. Non-compensatory factors represent the most important factors in the purchase decision process and are used to eliminate options in the initial phase using a non-compensatory strategy. Weighted adding factors represent those factors in the innovation adoption process used to derive at a purchase decision in the second phase using a weighted adding strategy. Non-compensatory factors will always have priority in the innovation adoption process over weighted adding factors. Additionally, weighted adding factors possess different levels of importance on the final decision depending on the impact of the noncompensatory variables and the context. If a decision still can't be made after the two elimination phases then an option is selected based on price/performance. The non-compensatory and weighted-adding factors are listed in Table 3. Findings on each factor are discussed below.

Table 3. Factors included in each Decision Strategy

\begin{tabular}{|c|c|c|}
\hline $\begin{array}{l}\text { Elimination } \\
\text { Phase }\end{array}$ & Strategy & Factor \\
\hline 1 & $\begin{array}{l}\text { Non compensatory } \\
\text { Strategy }\end{array}$ & $\begin{array}{l}\text { - } \text { Budget } \\
\text { - Redundancy } \\
\text { - Organizational Strategy } \\
\text { - Life Expectancy } \\
\text { - Time } \\
\text { - Compatibility } \\
\text { - } \\
\text { Reputable Vendor }\end{array}$ \\
\hline 2 & $\begin{array}{l}\text { Weighted Adding } \\
\text { Strategy }\end{array}$ & $\begin{array}{ll}\text { - } & \text { Complexity } \\
\text { - } & \text { Social Pressure } \\
\text { - } & \text { IT support } \\
\text { - } & \text { Price } \\
\text { - } & \text { Perceived Innovation Characteristics }\end{array}$ \\
\hline
\end{tabular}




\section{Non-Compensatory Factors}

Non-compensatory factors represent factors in the initial phase elimination and are therefore considered the most important factors in the innovation adoption process. Their significance is nonnegotiable. As a result, the decision makers can exclude many options very quickly. Fred, for example, described the role of the non-compensatory factors in the following way:

There was quite a long list of requirements that actually made the decision quite a bit easier because it very quickly took [options] off the table.

Factors were characterized as non-compensatory because (1) no other factor was said to have an influence on them and (2) they were described by the participants as core factors. Seven factors were identified as non-compensatory: budget, redundancy, organizational strategy, life expectancy, time, compatibility, and reputable vendor.

\section{Budget}

Decision makers felt that their options were confined to how much funding they had available for the purchase. Andy indicated the factor's importance and priority on both adoption and nonadoption:

We are constrained by the amount of money we have. There's a set amount of money from the budget and then there's a set amount that has come from external funding. Those are the confines that we have to work within. There's a whole bunch of [hardware] that we would love to have but at this point, a decision had to be made that the finances were not there to obtian those.

Several decision makers referred to budget as the basis for their decision because it eliminated all other options. Fred suggested that the department may have selected a different product if there were more funding from other faculties. When there were no options that met the budget criteria, decision makers could not compromise the importance of budget and were forced to postpone their decisions until the budget changed. As Fred stated below:

We were very impressed with the product, we continued to demo it and investigate it for a couple of months. But, unfortunately, budget cuts were happening at the university, and no decisions could be made from the time we demoed it in the fall until the end of the spring semester.

Thus, budget was identified as a non-compensatory factor because decision makers indicated that it was a core factor that could not be compromised.

\section{Redundancy}

Decision makers indicated that redundancy was critical to ensure zero downtime and good job performance. Garth illustrated why redundancy was so critical for the decision:

From the server side, I wanted to prove that I could do the job properly, and our goal was zero down time. We didn't want to leave any of the students or faculty hanging without a properly functioning network.

Redundancy was also shown to be the basis for the final decision. Garth described this final decision:

We got a pair of servers because they gave us a two for one deal. Originally I thought that it would be cool to have two exact sets of hardware in case one died then we could just swap the hard drives. Essentially, the primary functionality keeps going while the secondary one goes on the back burner for a while. 
In the context of non-adoption, decision makers had to reject their preferred option due to redundancy. In the passage below, Bob explained how the innovation was not adopted because of both the budget and redundancy requirements:

We decided to stay with the [old hardware] because [the innovation] required an [additional hardware] and there's a cost associated with that [hardware] and we needed redundancy... We didn't have enough of a budget to allow for the [innovation] and the cost associated with the [additional hardware].

The demonstration of redundancy's effect on the decision indicated that decision makers felt that redundancy was a non-compensatory factor in the innovation adoption process.

\section{Organizational strategy}

Ensuring that the decision was congruent with the institution's mission and strategic plan was very important to decision makers because it moved the institution forward. Meeting the needs of the institution was expressed as part of the decision makers' core values as an employee at the institution. Fred described how organizational strategy was fundamental to the purchase decision and more important than other factors, such as complexity:

It doesn't matter what we've used historically, what we've used in the past, or what we currently use. We need to find the best solution that meets the needs of our institution and our users and we move in that direction.

Fred also portrayed organizational strategy as a key factor in the innovation adoption process because it complemented the requirements of the decision maker's department. Fred expressed how his department's role was congruent with the organization's strategic plan:

We always look at our technology purchases from a pedagogical perspective and ask, how is this [innovation] going to support the learning environment at [this institution]?

Our decision is not based on what other institutions are doing but on our population and how we can best position [this institution] strategically.

As presented above, participants in this study believed in the organizational values of their institution and followed the requirements imposed by department members. Both points are found to be key components of organizational commitment (Buchanan, 1974). Organizational commitment refers to the relative strength of an individual's identification with and involvement in a particular organization (Steers, 1977). One of the outcomes of a manager with high organizational commitment is dedication to sustaining the wellbeing of the organization (Buchanan, 1974). The decision makers in this study support these classical findings in the organizational commitment literature because they not only made statements that characterized the phenomenon but also adopted innovations based on the organizational strategy. Garth stated that his decision making unit adopted an innovation because of the organizational strategy to develop the institution, "We did change technologies in order to make future acquisitions easier with expansion [of the organization]." The demonstration of organizational commitment and its effect on the purchase decision indicated that decision makers felt that organizational strategy was a non-compensatory factor in the innovation adoption process.

\section{Life expectancy}

Life expectancy is a period of time specified in organizational decisions for which computer hardware is to be used before becoming technologically obsolete. It was identified as a noncompensatory factor because it is a requirement that the institution places on all innovation purchases. As Andy commented: 
We have different evergreen cycles or refresh cycles for the equipment that we buy. First, we have a dollar figure that we have to stay within, and second, there's a pre-determined life expectancy of the equipment so we have to match that as well.

Life expectancy was also described as a factor that was always considered before the purchase decision. Evan explained how the innovation is selected based on both budget and life cycle requirements:

We always try to aim for a certain price range between [thousands of dollars]. That way we get a very high end computer for the faculty that will last them a guaranteed three years.

As a result, life expectancy was listed as a non-compensatory factor in the innovation adoption process.

\section{Time}

The decision makers in this study used time to refer to the timeframe available to make the decision. Time had a huge effect on non-adoption. As Fred stated:

It was [an expensive] decision and it would have been nice to have more time the other faculty that was originally involved regretted not getting on board with it.

Consistent with multiple studies (Bettman et al., 1998; Ozanne \& Churchill, 1971; Payne et al., 1988), time constraints influenced the effect that other factors had on the final decision. Fred further described how time affected his cognitive process when making the final decision:

It really came down to a fairly quick meeting between my department, the faculty, and the IT staff regarding whether or not we should gamble on this [innovation].

Furthermore, when there was more time available, decision makers were able to increase their cognitive processing and therefore make better purchase decisions. As Andy stated:

[The purchase decision] was a very long, lengthy process that took about 2 years. However, we usually carry out that process so we're not just duplicating how we build labs and stamping it in another room. We try to change that process to see if there's a better way to build it.

Thus, the amount of time allotted to make a decision affects other factors in innovation adoption. Since time was also expressed as a core factor by the decision makers, it was categorized as a non-compensatory factor.

\section{Compatibility}

The decision makers expressed that compatibility limited their options and was the basis for their final decision. As Bob stated:

It wasn't a tough decision because of the fact that you want to keep things compatible with your existing stuff; it was kind of a no brainer.

For the majority, lack of compatibility forced the rejection of a certain innovation. As Cam stated:

[One vendor] built in-house software that was supposed to perform this [task] but when they showed us, it didn't run on an Apple [computer] and it had some other [compatibility related] issues. So we were like 'ehh no, you guys are eliminated'.

Unsurprisingly, compatibility also forced decision makers to continue adopting innovations from the same vendor. Garth stated: 
We got some machines that are close to 10 years old and some others that we had just bought the last year. And [all the machines] were [from the same vendor]; they all worked pretty nicely together. So the idea of dropping any [other hardware] in the mix was pretty much a bad idea.

Since compatibility was shown to affect adoption and other factors in the innovation adoption process, it was identified as a non-compensatory factor.

\section{Reputable vendors}

It was a minimum requirement from all the decision makers that the innovation had to come from a reputable vendor. As Andy stated:

The vendors that actually proposed, two of them we had worked with before. The other two, some of our colleagues in IT had worked for. They were all at least [reputable] companies.

In fact, a reputable vendor was so important to these decision makers that they often made specific business trips to evaluate the vendors' capabilities. Andy further described this process in the following way:

We had them respond and give us references and give us tours of the other companies they had worked for, so we could see how that performance met up on that end.

The significance of selecting a reputable vendor mostly related to previous bad experience that the decision makers had with smaller vendors. The decision makers in this study did not believe that smaller vendors could provide the technical support and service that they required. Bob explained how their previous negative experience with a small vendor forced them to start considering a more reputable vendor:

We're not a big company but we've been bitten in the past where we went with a small vendor and they weren't big enough to service the needs when we came [to them with an issue].

Interestingly, in the past, these decision makers employed a compensatory strategy rather than a non-compensatory strategy related to vendor. They assumed that a good value on one attribute (e.g., price) can compensate for a poor value on another (e.g., less reputable vendor). However, they found that the price break could not compensate for a less reputable vendor. Therefore, the decision makers in this study had to instead implement a non-compensatory strategy that amended the reputable vendor factor into a fixed factor that could not be compromised. As Cam stated:

A couple years ago we had a company in here which wasn't a [reputable] hardware [vendor]. We went with them for a few years because they were cheaper but the machines that we were getting were just constantly having issues.

The decision makers still consider the reputable vendors factor to be non-compensatory with other factors such as price. Dale stated:

There are lots of other smaller vendors out there that we might be able to get a little bit of a better price break, but then of course there's always the concern of them being able to maintain, service, and technically support us.

Although the type of vendor may not have originally been a non-compensatory factor, the decision makers in this study perceived reputable vendors as a non-compensatory factor after their negative experience with a small vendor. 


\section{Weighted Adding Factors}

The weighted adding factors are used during the second phase of elimination of the combined strategy. Their value in the purchase decision is determined through the weighted adding strategy. Some weighted adding factors may have limited impact on the final decision because they conflict with the non-compensatory factors. For example, a non-compensatory factor such as compatibility may make a weighted adding factor such as price less important to the final decision because the need to have compatible innovations eliminated the cheapest options. Thus, weighted adding factors are less important in the innovation adoption than non-compensatory factors.

The importance of each variable factor may also vary. Consequently, depending on the context, some weighted adding factors may have more of an impact on the final decision than others. For example, a decision maker may select an option because of the intense social pressure to do so even though that option includes high switchover costs. If those were the only two variable factors under consideration, the weighted adding strategy suggests that the social pressure factor was assessed as more important than the switchover costs factor by the decision maker. In addition, good values for some weighted adding factors can compensate for poor values on others. Therefore, the option with the highest overall value is selected. Cam described how the innovations were compared to one another:

I wanted to make sure that whatever [hardware options] we were comparing had a good, similar price. Whether the sticker says [one brand] or if it says [another brand], it doesn't matter. The parts inside are the same.

In the above example, it can be seen that the weighted adding factor, price, was weighted higher than another potential variable factor, brand.

Factors were included in this category for three reasons: (1) they were identified as an important factor in the innovation adoption process; (2) they can be compromised by a non-compensatory factor; and (3) they have been compared with other weighted adding factor(s) to come up with a final decision. Five factors were identified as weighted adding factors: complexity (ease of use), social pressure, IT support, price, and perceived innovation characteristics.

\section{Complexity (ease of use)}

Rogers (1995a) defined complexity as the degree to which using a particular innovation is free of effort. This factor is conceptually similar to what in other frameworks is termed as ease of use. Decision makers believed that standardization made an innovation easier to use. Standardization not only ensured that the end-users knew how to use the innovation but also made the innovation easier to support from an IT perspective. Garth described the importance of standardization for decreased complexity in the following way:

[The vendor's] model stays set and I know exactly what I'm getting inside [the product]. If I buy 30 units today and then buy 5 more units 3 months later, I know I'm getting the same hardware. So that consistency factor is a big selling point.

In the context of non-adoption, complexity contributed to temporary non adoption in some situations. However, those innovations were adopted over time as complexity decreased. Andy described this concept in the following way:

We decided to make somewhat of a staged approach where we would bring in new resources every year and as people get familiar with them and are using them the way that they should, then we'll continue to build that resource base.

However, complexity was found to be directly affected by budget, compatibility, and organizational strategy. This perception was illustrated earlier by Fred who explained that complexity was 
an important factor in the purchase decision only after they accounted for the institution's organizational strategy. Furthermore, Bob described how ease of use was advantageous if it was in their budget. They would not require additional equipment to power or cool the innovation. In that case, Bob stated:

Assuming we had the budget to do so, there are some advantages to [the other option]. They use less power. They use less cooling. And typically if you can fill up the chassis, they are less expensive to utilize as well.

To the majority of decision makers, compatibility tremendously affected the impact that complexity had on the final decision. Evan described how standardization could not be a factor in the final decision because it conflicted with the non-compensatory factor, compatibility:

We have standardized [with a specific vendor] for the last seven years that we've been involved in this [technology], with exception of one faculty that has [a different vendor]. When we started looking at this [technology], the initial response from the IT department was it's not [our preferred vendor]. Luckily, at the time the solution from [that preferred vendor] didn't work on the Mac side. It's a PC-only solution. So that [problem] very quickly became a view point.

Additionally, once the minimum requirement for compatibility was met, decision makers were allowed to consider complexity. Evan further described this relationship in the following way:

It's simple and everyone here is used to it now. It's compatible enough now that there's no reason to change.

Decision makers admitted that although complexity was not the basis for the final decision, it still made some options more attractive than others. Bob stated:

One of the things that you have to consider is the learning curve associated with implementing a new piece of hardware or new vendor. So if all things were equal, I probably still would have chosen [that vendor]. That was who we were familiar with and that was who we had experience with.

Thus, although complexity was deemed by the decision makers as an important factor in the innovation adoption process, its impact was only important after other non-compensatory factors were addressed.

\section{Social pressure}

Social pressure was different from the other weighted adding factors in that it only became important to the purchase decision if the decision maker's experience with the purchasing process or the innovation was limited. When experience was limited, decision makers adopted innovations based on the advice of their superior or at least a credible source that had the necessary experience. These findings are consistent with results in the technology acceptance literature indicating that reliance on other's opinions is only significant in mandatory situations (Hartwick \& Barki, 1994), predominantly in the early stages of experience when an individual's opinions are reasonably lacking adequate or proper knowledge or information (Agarwal \& Prasad, 1997;

Hartwick \& Barki, 1994; Karahanna et al., 1999; Taylor \& Todd, 1995; Thompson, Higgins, \& Howell, 1994; Venkatesh \& Davis, 2000; Venkatesh, Morris, Davis, \& Davis, 2003). This normative pressure will diminish over time as increasing experience provides a more instrumental (rather than social) basis for individual intention to adopt the innovation (Venkatesh et al., 2003). Dale admitted that lack of experience often calls for help from a supervisor. Dale said,

There are people that provide their opinions for sure. I wouldn't say they influenced [my decision]... other than my supervisor with whom I talk about big purchases. I'll just 
make sure that [my decision is reasonable], especially with me being new here and just starting [this position a couple months ago]. There are still a lot of questions that I have.

Other decision makers who currently possess high experience recalled that they depended on their supervisor when they first started working in their position. Garth stated:

I was under the direction of the people that came before me. All of our hardware was [from the same vendor] and I certainly didn't feel confident to make any drastic changes at that point.

Although decision makers may have a lot of experience with purchase decisions, they may still lack experience with a specific [innovation]. If a decision maker was unfamiliar with an innovation then the effect of social pressure on the purchase decision increased. As Evan stated:

I hadn't really used [the innovation] much before so I was relying a lot on what other people were saying and what [another department] had recommended from their experience.

In addition, when the decision maker was unfamiliar with a specific product then they also sought advice from not only their supervisors (see above quote) but also external consulting companies. Andy stated:

We don't assume that we know all that we need to know. So we usually partner with a series of external vendors, bring them into the loop on what we would like to do and get them to start presenting on the different components, the different manufacturers, the different products that they think that we should use so we start building our understanding of what's out there.

Decision makers felt that social pressure wouldn't have been so high if they were familiar with the product. Evan spoke of the effect that product experience has on accepting outside advice:

I was much more reliant on outside opinions than I would be with other things such as buying a computer where I knew the insides totally or what every number means and what every piece does inside out.

To further establish the effect of experience on social pressure, decision makers expressed that high experience reduced social pressure. Andy described this phenomenon in the following way:

We usually don't involve the different areas inside of the institution because we feel that that knowledge is really established within [my colleague] and I and we go ahead and execute on those decisions.

The decision makers in this study argued that the role of social pressure was less important because of the technical nature of the adoption decisions. They posited that social pressure from end users had limited impact due to the social groups' lack of knowledge about IT. As Andy commented,

When somebody wants to do something technical they bring it to me and say 'how do we do this?' So there's not a lot of knowledge outside [of the IT department].

As a result, social pressure was noted as having an effect on the innovation adoption process but experience and the technical nature of these decisions often reduce its influence. However, experience and the technical nature of these decisions were not found to directly influence innovation adoption and were therefore not included as a factor. 


\section{IT support}

IT support strongly relates to the construct 'facilitating conditions' in Venkatesh and colleagues' (2003) Unified Theory of Acceptance and Use of Technology. Facilitating conditions refers to the degree to which decision makers believe that an organizational and technical infrastructure exists to support the use of the innovation (Venkatesh et al., 2003). IT support is similar to facilitating conditions in that they were both designed to remove barriers in the technological and/or organizational environment. These aspects of the technological and organizational environment include resources and knowledge to use the system, control over the system, specialized training concerning the innovation, and a person or team available to resolve innovation difficulties (Venkatesh et al., 2003). However, facilitating conditions also considered compatibility as a core construct. Although compatibility was expressed as a construct of facilitating conditions, it could not be included in IT support because it was expressed by the participants as a non-compensatory factor whereas the other constructs in facilitating conditions were described as weighted adding factors. Therefore, IT support is not the same as facilitating conditions.

The non-compensatory factor of organizational strategy directly influenced the effect that IT support had on innovation adoption. Specifically, decision makers had to compromise their ability to support the innovations in order to implement the organizational strategy. As Evan stated:

[Organizational strategy] has made my job more difficult. I have to make arrangements with faculty to bring their computer in when I need to do something with them. So it's a little more work that way. But the benefits are so great for what it's done for our faculty-to allow them to take these computers with them anywhere.

In addition, the weighted adding factor, social pressure, was weighted higher than IT support (when experience was low). Decision makers had to overcome their personal barriers to use the innovation because of the social pressure to do so. Evan allowed social pressure to transform his understanding of a particular brand, saying:

At that point, I just wasn't quite sure that [the innovation] was the way to go. I was scared, myself. But the faculty was already using it. They seemed happy. The schools were using them too, so I decided to go with it.

Although IT support was devalued by non-compensatory factors and weighted less than other weighted adding factors, it is still important in the innovation adoption process. Decision makers admit that although IT support is sometimes overlooked, it is still important to the purchase decision. Fred spoke about how IT support was important to his decision but often neglected in other people's decisions:

[The purchase decision] actually came down to a cost analysis between the various products we were looking at and what it would cost from an IT perspective here to support [the innovation]. And those are a lot of costs that people don't consider when they're looking at hardware and software solutions. Quite often you only look at the purchasing cost and not the ongoing administrative costs that are associated with the purchase. So [IT support] was a big part of the decision.

IT support even had the ability to reduce risk in the innovation adoption process. Decision makers felt that risk associated with the innovation was reduced when there were people available who could merge the innovation into the current system. As Bob stated:

The consultants themselves have included in the price their services to come in and do the migration for us. So the migration concerns and the headaches associated with that process was gone. There was no risk there or at least they had assumed most of the risk. 
Although IT support was described as an important factor in the innovation adoption process, its influence was often affected by other factors such as organizational strategy and social pressure. Thus, IT support was identified as a weighted adding factor.

\section{Price}

With the tremendous importance of budget, it was surprising to discover that price (tangibles and intangibles) was not only compromised by non-compensatory factors but was also weighted lower than some other weighted adding factors. Decision makers were found to value other weighted adding factors such as perceived innovation characteristics and IT support more than price. Additionally, non-compensatory factors such as time directly compromised the impact of price on the innovation adoption process. Cam, who considered perceived innovation characteristics more important than price, stated:

[The innovation] was green, efficient and more cutting-edge... So we thought, well, for 30 bucks more per machine, yes, it's a bit more than we wanted to spend but it's a huge jump forward for the students who are going to get to take advantage of [the innovation] next semester.

Decision makers were especially likely to weigh IT support higher than price when making decisions that were very complex. Andy spoke of a decision whether or not to purchase a very expensive, complex and innovative information system:

They cost more money but the resource that they put on this project had every single certification that the company offered and had between 4-5 times the years of experience with the application that we were using. Additionally, this individual that we were quite interested in, he had actually built [these systems] on the technology side. So there was a real source of knowledge that he presented.

Nonetheless, price was still an important weighted adding factor in the innovation adoption process. Price was the basis for the final decision when options were still available after accommodating the non-compensatory factors and weighting the weighted adding factors. Fred looked at the cost analysis because there were two products that met all the criteria. He stated:

The actual decision came down to two products that met all the criteria of the minimum requirements that we had listed then it just went to a price decision. Once we compared them side by side and looked at the cost analysis, one of the technologies came at a third of the price and still met all the needs, in fact, in my opinion, exceeded the first product.

Furthermore, decision makers, who had already decided on an option, changed their minds when they saw the price comparison. Fred spoke about a financial officer who instantly changed their final decision once they saw the price comparison:

But what was really neat, was once we showed [our financial officer] the price comparison, the decision changed instantly because it was going to cost them a third of the price.

Thus, price was identified as a weighted adding factor because non-compensatory factors were considered more important and it was compared to other weighted adding factors to make a purchase decision.

\section{Perceived innovation characteristics}

Many researchers have found that perceived innovation characteristics affected the innovation adoption process (e.g., Frambach \& Schillewaert, 2002; Ostlund, 1974; Rogers, 1995a). According to Waarts and colleagues (2002), perceived innovation characteristics are the organization's ideas about the value of the innovation - the total additional functionality or performance of the 
innovation for the organization. Value may be assessed in terms of increased revenues, flexibility in integrating business information over functional areas, the use of state-of-the-art technology, user-friendliness of the system, etc. It is considered together with the costs of adoption, to make the adoption decision (Waarts et al., 2002). Likewise, the decision makers in this study expressed the same relationship between value and total cost (tangibles and intangibles). Decision makers often considered innovation characteristics in conjunction with cost. Garth spoke about this priceperformance curve as follows:

Basically, [innovations] come out and they're fast, fast but incredibly expensive. Then as we move towards the center of the [price-performance] curve, they're not as fast but their price-performance ratio really, really improves. So we're looking for something between leading edge and high performance.

Decision makers were especially uninterested in expensive innovation characteristics that could be purchased later on at a discounted price. Evan stated:

Hard drive and memory can always be added later if you need to, so buying and paying a lot more initially is not worth it.

Despite this special relationship between innovation characteristics and price, the impact of innovation characteristics on the innovation adoption process was also directly affected by other noncompensatory and weighted adding factors. Some decision makers weighted IT support and innovation characteristics similarly and, therefore, had to come up with creative solutions that accommodated both weighted adding factors. As Andy stated:

We decided to make somewhat of a staged approach where we would bring in new resources every year and, as people get familiar with them and are using them the way that they should, then we'd continue to build that resource base.

When the non-compensatory factor of time had to be accommodated, IT support became more important than innovation characteristics. As Bob stated,

That technology was still complex and we had nobody who had expertise in it. We are a little bit under a time frame crunch. And we thought that we didn't want to take the time for someone to be trained in that technology and go through the process of that training.

Innovation characteristics were also directly affected by the non-compensatory factor, life expectancy. Specifically, when decision makers saw that some beneficial innovation characteristics conflicted with the life expectancy requirement, those innovations had to be removed as options for the final decision. Evan had been considering a high-end innovation, but, had to stop considering the innovation after product testing revealed an issue with life expectancy. He explained,

The reason we don't go with those [high end computers] is that we had a few in here before and every one of them has been dropped and damaged and destroyed. So eventually we just decided that this must be because they are too big.

Perceived innovation characteristics was thus labeled as a weighted adding factor because its influence was affected by other non-compensatory and weighted adding factors, such as time, price, life expectancy, and IT support.

\section{Discussion}

This research explored how IT professionals make purchase decisions in innovation adoption. Classic decision strategies (see Bettman et al., 1998) in the consumer choice literature were found to explain purchase decisions in innovation adoption for IT professionals in a post-secondary educational setting. First, we asked how IT professionals in a post-secondary, educational setting 
describe their decision to adopt an innovation. The participants were found to use a staged approach to purchase decisions in innovation adoption. Options that did not meet key criteria were immediately eliminated. If there were still options available after the first stage, participants used certain factors to weigh each option then selected the option with the highest score.

Next, we asked if different levels of impact could be identified with each factor influencing the purchase decision. The results suggest that the factors affecting the purchase decision were not equal. Options that did not meet the minimum requirements set out by the non-compensatory factors were eliminated. A good value in one factor cannot make up for a poor value in another. The non-compensatory factors from the initial phase were budget, redundancy, organizational strategy, life expectancy, time, compatibility and reputable vendor. Other factors (weighted adding factors) would then be used to analyze the remaining purchase options in more detail. Participants examined each weighted adding factor for that option, multiplying each attribute's assigned subjective value by its importance weight, and summing these products across all of the attributes to obtain an overall value for each option. The option with the highest overall value was then selected. The weighted adding factors from the second phase were complexity (ease of use), social pressure, IT support, price and perceived innovation characteristics.

Finally, we asked if there was a decision strategy that best describes the purchase decision process in innovation adoption. Participants were found to use a combined strategy in order to facilitate the purchase decision in innovation adoption. Participants recalled undergoing an initial phase in which some options were eliminated using a non-compensatory strategy and then a second phase in which the remaining options were evaluated by a weighed adding strategy.

Although factors affecting innovation adoption are well established in the adoption literature, the relationship between factors and how it affects innovation adoption in the adoption literature is limited. Given this insufficiency, the significant contribution of this research project is a more comprehensive understanding of the different factors and their level of impact in innovation adoption. These findings are consistent with the classic decision strategies in the consumer choice literature (see Bettman et al., 1998), where the concept of prioritizing factors is well developed. To our knowledge, this is the first project to explain innovation adoption with the classic decision strategies in the consumer choice literature.

These findings can not only expand the innovation adoption literature but also enhance B2B (business to business) marketing strategies used to influence innovation adoption. Marketers must not only identify the important factors affecting innovation adoption but also how these factors interact with each other. Sales personnel can use these findings to explain adoption and nonadoption of an innovation. Innovations and their corresponding marketing strategy could then be improved to meet the minimum requirements of the non-compensatory factors and have the highest score based on the weighted adding factors. Furthermore, the post-secondary educational setting allows marketers to better understand a subset of their customer base who are under studied but major investors in IT (Elpez \& Fink, 2006).

The purpose of this study was not to make broad generalizations about the innovation adoption process but rather to come to an in-depth understanding of the factors that affect innovation adoption in the sample studied. Nonetheless, in order to expand this understanding further, it would be useful to broaden the sampling frame to include decision makers from a larger pool of organizations in the public sector. Factors in the innovation adoption process may be related, in part, to the organizational culture. Greater variance among organizations in the public sector would provide more detail as to the ways that factors affect the innovation adoption process under varying organizational cultures.

The exploratory design of this study only includes factors reported by the participants themselves. Therefore, this study does not preclude the existence of other factors that may influence the inno- 
vation adoption process. For example, existing process models included trialability (e.g. Rogers, 1995a) as a factor affecting innovation adoption. Thus, while the factors discussed above could generalize to other innovation adoption situations, the weight and category of each factor in this study may indeed be restricted to a specific form of innovation adoption in the public sector.

In addition, the data does not speak to the decision maker's personal characteristics that may influence the innovation adoption process. Clark-Murphy (2010) has demonstrated that the decision maker's subjective interpretation of the environment contributes to differences in individual decision making. It would be useful to determine whether factors related to the innovation adoption process also become more or less important depending on the personal characteristics of the decision maker. Other factors could also play a role, like organizational values and practices related to IT and information systems (Travica, 2008). For example, once vested in a product they value as technologically progressive, IT professionals may regularly eliminate other options.

Finally, this study did not employ a longitudinal design but relied upon reflective narratives of past experiences. Following IT decision makers throughout the innovation adoption process (i.e., from pre adoption to post adoption) would provide a more in-depth, comprehensive understanding of changes in the factors that affect innovation adoption over time.

In summary, this research demonstrated that innovation adoption can be explained by the combined strategy in the consumer choice literature. By showing that the factors in the innovation adoption process are unequal, it has provided a valuable step forward for researchers seeking new theories to explain innovation adoption.

\section{References}

Agarwal, R., \& Prasad, J. (1997). The role of innovation characteristics and perceived voluntariness in the acceptance of information technologies. Decision Sciences, 28(3), 557-582.

Ajzen, I. (1985). From intentions to actions: A theory of planned behaviour. In J. Kuhl \& J. Beckmann (Eds.), Action-control from cognition to behavior (pp. 11-39). New York: Springer.

Ajzen, I. (1991). The theory of planned behavior. Organizational Behavior and Human Decision Processes, 50, 179-211.

Anderson, J. C., Thomson, J. B. L., \& Wynstra, F. (2000). Combining value and price to make purchase decisions in business markets. International Journal of Research in Marketing, 17(4), 307-329. doi: 10.1016/s0167-8116(00)00029-X

Benbasat, I., \& Barki, H. (2007). Quo vadis, tam? Journal of the Association for Information Systems, 8(4), 211-218.

Bettman, J. R., Luce, M. F., \& Payne, J. W. (1998). Constructive consumer choice processes. The Journal of Consumer Research, 25(3), 187-217.

Bouchbout, K., \& Alimazighi, Z. (2008). A framework for identifying the critical factors affecting the decision to adopt and use inter-organizational information systems. World Academy of Science, Engineering and Technology, 33, 348-355.

Buchanan, B. (1974). Building organizational commitment: The socialization of managers in work organizations. Administrative Science Quarterly, 19(4), 533-546.

Bunn, M. D. (1993). Taxonomy of buying decision approaches. The Journal of Marketing, 57(1), 38-56.

Burns, T., \& Stalker, G. M. (1961). The management of innovation. London: Tavistock Publications.

Cabral, L. M. B., Salant, D. J., \& Woroch, G. A. (1999). Monopoly pricing with network externalities. International Journal of Industrial Organizations, 17(2), 199-214

Clark-Murphy, D. (2010). Do interactive theories really explain public sector managerial decision-making? Asian Social Science, 6(3), 17-26. 
Davis, F. D. (1989). Perceived usefulness, perceived ease of use, and user acceptance of information technology. MIS Quarterly, 13(3), 319-340.

Davis, F. D., Bagozzi, R. P., \& Warshaw, P. R. (1989). User acceptance of computer technology: A comparision of two theoretical models. Management Science, 35(8), 982-1003.

Del Aguila-Obra, A. R., \& Padilla-Meléndez, A. (2006). Organizational factors affecting internet technology adoption. Internet Research, 16(1), 94-110.

Dewan, S., \& Riggins, F. J. (2005). The digital divide: Current and future research directions. Journal of the Association for Information Systems, 6(12), 298-336.

Eckhardt, A., Laumer, S., \& Weitzel, T. (2009). Who influences whom? Analyzing workplace referents' social influence on it adoption and non-adoption. Journal of Information Technology, 24, 11-24.

Elpez, I., \& Fink, D. (2006). Information systems success in the public sector: Stakeholders' perspectives and emerging alignment model. Issues in Informing Science and Information Technology, 3, 219-231.

Eriksson, P., \& Kovalainen, A. (2008). Qualitative methods in research. Los Angeles: SAGE.

Fiegenbaum, A., Hart, S., \& Schendel, D. (1996). Strategic reference point theory. Strategic Management Journal, 17(3), 219-235.

Fishbein, M., \& Ajzen, I. (1975). Belief, attitude, and behavior: An introduction to theory and research. London: Addison-Wesley.

Frambach, R. T., \& Schillewaert, N. (2002). Organizational innovation adoption: A multi-level framework of determinants and opportunities for future research. Journal of Business Research, 55(2), 163-176. doi: $10.1016 / \mathrm{s} 0148-2963(00) 00152-1$

Gladstone, J. W., Dupuis, S. L., \& Wexler, E. (2006). Changes in family involvement following a relative's move to a long-term care facility. Canadian Journal on Aging, 25(1), 93-106.

Guba, E. G., \& Lincoln, Y. S. (1989). Fourth generation evaluation. London: Sage Publications Inc.

Hartwick, J., \& Barki, H. (1994). Explaining the role of user participation in information system use. Management Science, 40(4), 440-465.

Hirschheim, R. (2007). Introduction to the special issue on 'quo vadis tam - Issues and reflections on technology acceptance research. Journal of the Association for Information Systems, 8(4), 203-205.

Holak, S. L., Lehmann, D. R., \& Sultan, F. (1987). The role of expectations in the adoption of innovative consumer durables: Some preliminary evidence. Journal of Retailing, 63, 243-259.

Iacovou, C. L., Benbasat, I., \& Dexter, A. S. (1995). Electronic data interchange and small organizations: Adoption and impact of technology. MIS Quarterly, 19(4), 465-485.

Jeyaraj, A., Rottman, J. W., \& Lacity, M. C. (2006). A review of the predictors, linkages, and biases in it innovation adoption research. Journal of Information Technology, 21(1), 1-23.

Karahanna, E., Straub, D. W., \& Chervany, N. L. (1999). Information technology adoption across time: A cross-sectional comparison of pre-adoption and post-adoption beliefs. MIS Quarterly, 23(2), 183-213.

Lapointe, L., \& Rivard, S. (2007). A triple take on information system implementation. Organization Science 18(1), 89-107.

Lincoln, Y. S., \& Guba, E. G. (1985). Natrualistic inquiry. Beverly Hills, CA: Sage.

McCracken, G. (1988). The long interview. New York: Sage Publications.

Nooteboom, B. (1989). Diffusion, uncertianty, and firm size. International Journal of Research in Marketing, 6(2), 109-128.

Ostlund, L. E. (1974). Percieved innovation attributesas predictors of innovativeness. Journal of Consumer Research, 1, 23-29. 
Ozanne, U. B., \& Churchill, G. A., Jr. (1971). Five dimensions of the industrial adoption process. Journal of Marketing Research, 8(3), 322-328.

Payne, J. W. (1976). Task complexity and contingent processing in decision making: An information search and protocol analysis. Organizational Behavior and Human Performance, 16(2), 366-387.

Payne, J. W., Bettman, J. R., \& Schkade, D. A. (1988). Adaptive strategy selection in decision making. Journal of Experimental Psychology: Learning, Memory, and Cognition, 14(3), 534-552.

Qualls, W. J., \& Puto, C. P. (1989). Organizational climate and decision framing: An integrated approach to analyzing industrial buying decisions. Journal of Marketing Research, 26(2), 179-192.

Ramdani, B., \& Kawalek, P. (2007). Smes \& is innovations adoption: A review \& assessment of previous research. Academia, Revista Latinoamericana de Admnistracion 39, 47-70.

Rogers, E. M. (1995a). Diffusion of innovations (4th ed.). New York: The Free Press.

Rogers, E. M. (1995b). Diffusion of preventive innovations. Addictive Behaviors, 27(6), 989-993. doi: 10.1016/s0306-4603(02)00300-3

Simon, H. A. (1955). A behavioral model of rational choice. The Quarterly Journal of Economics, 69(1), 99-118.

Steers, R. M. (1977). Antecedents and outcomes of organizational commitment. Administrative Science Quarterly, 22(1), 46-56.

Taylor, S., \& Todd, P. A. (1995). Assessing it usage: The role of prior experience. MIS Quarterly, 19(4), 561-570

Teo, T. S. H., Tan, M., \& Buk, W. K. (1997). A contingency model of internet adoption in Singapore. International Journal of Electronic Commerce, 2(2), 95-118.

Thompson, R. L., Higgins, C. A., \& Howell, J. M. (1994). Influence of experience on personal computer utilization: Testing a conceptual model. Journal of Management Information Systems, 11(1), 167-187.

Thong, J. Y. L. (1999). An integrated model of information systems adoption in small businesses. Journal of Management Information Systems, 15(4), 187-214.

Tornatzky, L. G., \& Klein, K. J. (1982). Innovation characteristics and innovation adoptionimplementation: A meta-analysis of findings. IEEE Transactions on Engineering Management, 29(1), $28-43$.

Travica, B. (2008). Influence of information culture on adoption of a self-service system. Journal of Information, Information Technology, and Organizations, 3, 1-15. Retrieved from http://jiito.org/articles/JIITOv3p001-015Travica470.pdf

Tversky, A. (1972). Elimination by aspects: A theory of choice. Psychological Review, 79(4), 281-299.

Venkatesh, V., \& Brown, S. A. (2001). A longitudinal investigation of personal computers in homes: Adoption determinants and emerging challenges. MIS Quarterly, 25(1), 71-102.

Venkatesh, V., \& Davis, F. D. (2000). A theoretical extension of the technology acceptance model: Four longitudinal field studies. Management Science, 45(2), 186-204.

Venkatesh, V., Davis, F. D., \& Morris, M. G. (2007). Dead or alive? The development, trajectory and future of technology adoption research. Journal of the Association for Information Systems, 8, 267286.

Venkatesh, V., Morris, M. G., Davis, G. B., \& Davis, F. D. (2003). User acceptance of information technology: Toward a unified view. MIS Quarterly, 27(3), 425-478.

Waarts, E., van Everdingen, Y. M., \& van Hillegersberg, J. (2002). The dynamics of factors affecting the adoption of innovations. Journal of Product Innovation Management, 19(6), 412-423.

Williams, M. D., Dwivedi, Y. K., Lal, B., \& Schwarz, A. (2009). Contemporary trends and issues in it adoption and diffusion research. Journal of Information Technology, 24, 1-10. 
Wolfe, R. A. (1994). Organizational innovation: Review, critique and suggested research. Joumal of Management Studies, 31(3), 405-430.

Zaltman, G., Duncan, R., \& Holbek, J. (1973) Innovations and organizations. New York: Wiley

\section{Biographies}

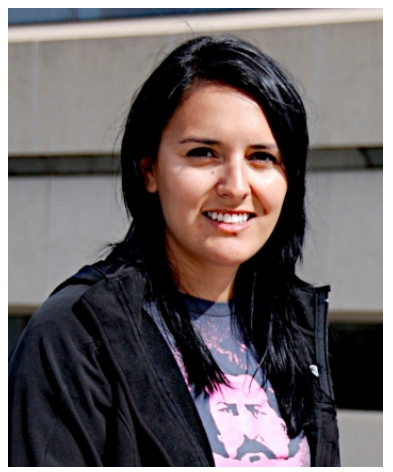

Katherine C. Lafreniere is a Research Associate in the multidisciplinary research project titled, Water: Making do with what we have, on behalf of the University of Lethbridge and Alberta Innovates in Alberta, Canada. She obtained her Bachelor of Management Degree in 2009 and Master of Science (Management) Degree in 2011 from the University of Lethbridge. Her research interests in the marketing area include decision making and consumer choice models; and applying social marketing thought to a variety of environmental issues.

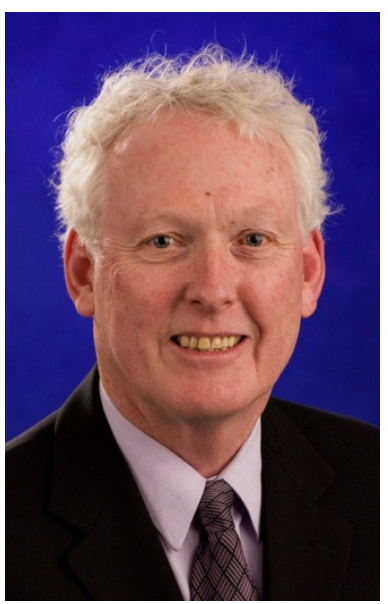

Dr. M. Gordon Hunter is a Professor Information Systems in the Faculty of Management, University of Lethbridge, Alberta, Canada. He has been appointed Visiting Professor, London South Bank University. He has held visiting positions at universities in Australia, England, Germany, Monaco, New Zealand, Poland, Turkey, and USA. In 2009 Gordon was a Fellow at the University of Applied Sciences, Munich, Germany. During 2005 Gordon was an Erskine Fellow at the University of Canterbury, Christchurch, New Zealand. Gordon's research approach takes a qualitative perspective employing Personal Construct Theory and Narrative Inquiry to conduct in depth interviews. He applies qualitative techniques in interdisciplinary research such as small business, agricultural management, governance of intellectual assets, and cross-cultural investigations. His current research interests in the information systems (IS) area include the effective management of IS personnel; the role of Chief Information Officers; and the use of IS by small business.

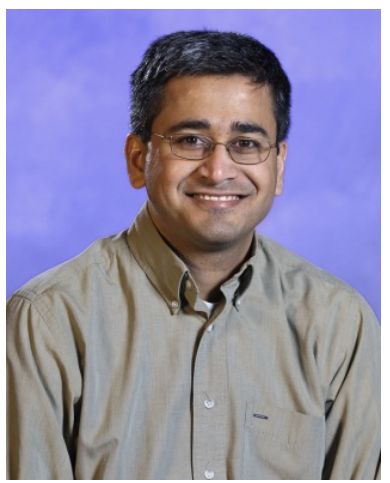

Sameer Deshpande is an Associate Professor of Marketing in the Faculty of Management and faculty member of the Centre for Socially Responsible Marketing at the University of Lethbridge, Canada. His research interests include applying social marketing thought to a variety of public health issues. He has published his research in several academic journals and books. Additionally, he has offered social marketing workshops to several non-profit and government agencies primarily in Canada. He serves as advisor on governmental and on governmental social marketing campaign teams. 